\title{
Protective Effects of Omega Supplement on Induced Hepatic Mal-Function by Thioacetamide in Male Rats
}

\author{
Davood Moghadamnia, ${ }^{1,2,}$ Mokhtar Mokhtari, ${ }^{3}$ and Saeed Khatamsaz ${ }^{3}$ \\ ${ }^{1}$ Department of Biology, Fars Science and Research Branch, Islamic Azad University, Fars, Iran \\ ${ }^{2}$ Department of Biology, Shiraz Branch, Islamic Azad University, Shiraz, Iran \\ ${ }^{3}$ Department of Biology, Kazerun Branch, Islamic Azad University, Kazerun, Iran \\ "Corresponding author: Davood Moghadamnia, Department of Biology, Fars Science and Research Branch, Islamic Azad University, Fars, Iran. Tel: +98-9173874503, E-mail: \\ davood.moghadamnia@gmail.com
}

Received 2016 February 25; Revised 2016 October 18; Accepted 2017 March 19.

\begin{abstract}
Background: Exposure to thioacetamide causes hepatotoxicity and hepatocellular carcinoma in human, while fish oil omega-3 supplement has anti-inflammatory effects.

Objectives: In this study, the protective effect of fish oil omega-3 supplement against induced hepatic mal-function by thioacetamide in rat is investigated.

Methods: In this experimental study, 42 male rats were divided into 6 groups of seven. The control group, the sham 1 group receiving $0.4 \mathrm{~mL} / \mathrm{kg}$ olive oil as the solvent of fish oil omega-3 supplement, the sham 2 group inter peritonealy receiving a dose of $150 \mathrm{mg} / \mathrm{kg}$ thioacetamide at the end of the experiment, the experimental groups 1, 2 and 3 orally receiving a daily dose of 100, 200 and 300 $\mathrm{mg} / \mathrm{kg}$ fish oil omega-3 supplements respectively for 3 month followed by an inter peritoneal dose of $150 \mathrm{mg} / \mathrm{kg}$ thioacetamide at the end of the experiment. The serum levels of SGOT, SGPT, ALP, GGT, LDH, albumin, bilirubin and total protein were measured. Following hematoxylin-eosin staining, liver tissue samples were pathologically studied. The data were analyzed by SPSS-18 program and using one way ANOVA and Tukey as post hoc test.

Results: The mean concentration of SGPT and bilirubin showed a significant decrease in the experimental group 1 compared to the group receiving thioacetamide. Similarly, the mean level of Albumin showed a significant reduction in experimental groups 1, 2 and 3 receiving thioacetamide. Also, the mean concentration of GGT in the experimental groups 1 and 2 compared to the group receiving thioacetamide decreased significantly; whereas, the mean levels of LDH, ALP, SGOT and total protein showed no significant changes in the experimental groups 1,2, and 3. Finally, the tissue changes in all three experimental groups improved compared to the group receiving thioacetamide, and these effects were dose-dependent $(\mathrm{P}<0.05)$.

Conclusions: The results of this study indicate that fish oil omega-3 supplement has a protective effect on induced hepatic malfunction by thioacetamide in rat.
\end{abstract}

Keywords: Fish Oil Omega-3 Supplement, Thioacetamide, Hepatic Mal-Function, Male Rat

\section{Background}

Liver diseases are considered one of the most important causes of death in the world [1]. Oxidative stress is known as a mechanism involved in the onset and progress of hepatic damages [2]. The increase in the levels of reactive oxygen and nitrogen species can cause hepatocellular injuries [3].

Unsaturated fatty acids are named according to the location of double bond from the carbon of the terminal methyl called omega carbon. The fatty acids, eicosapentaenoic acid (EPA) and docosahexaenoic acid (DHA) belong to the omega-3 fatty acid category. These acids can't be synthesized by humans and should be included in diet; the main sources of omega-3 are fish oil, marine planktons and oceanic fish [4]. In a study, Wergedahl et al. showed that combination of fish oil (FO) and fish- protein hydrolysate (FPH) reduces plasma cholesterol levels, which are related to their effects on the reduction of HDL cholesterol level, while the total hepatic cholesterol concentration increased, compared to control mice and those receiving FPH and FO alone. The cholesterol reducing effects of combined FPH and FO is related to decreased secretion of low density lipoproteins (LDL) from the liver [5]. The studies of Kim et al. demonstrated that omega-3 fatty acid has protective effects against insulin resistance induced by obesity and liver steatosis. Omega-3 hyperlipidemia induced by diet and fatty liver can be improved through induction of cytochrome CYP7A1 expression and the activity of cholesterol catabolism to bile acids [6]. In a study by Haast et al., a direct correlation was found between Omega-3 fatty acid intake and reduced agerelated brain deterioration and damage [7]. Also, Siegel et al. showed that omega-3 fatty acids have beneficial effects 
on cerebral-cardiovascular diseases [8]. Likewise, fish oil omega-3 emulsion significantly reduces hepatic damage following liver transplantation [9], and has protective effects against liver fibrosis and injuries as well as oxidative stress induced by carbon tetrachloride [10]. Administration of omega-3 fatty acids may reduce infection rate and improve liver function recovery in HBV-associated hepatocellular carcinoma patient after hepatoctomy. This improvement is associated with suppressed production of proinflammatory cytokines in these patients [11].

Thioacetamide (TAA) is an organic compound containing Thiono-sulfur that is used as a fungicide, an organic solvent and a stabilizer of motor oil. In 1984, Hugh and Nelson first reported that TAA is a hepatotoxic agent. A single dose of this agent can produce lobular necrosis sentry in animals, and chronic induction of thioacetamide can lead to liver cirrhosis and carcinoma [12]. The toxic effects of thioacetamide is due to its biological activity exerted through oxidase systems, particularly FAD mono oxygenases and CYP2E1 [13]. Hence, in conjunction with the measurement of hepatic enzymes, thioacetamide can be useful in pharmaceutical research to induce pathological condition, because many blood factors and enzymes are synthesized in hepatocytes and their measurement is a diagnostic criteria for liver function.

\section{Objectives}

Due to high prevalence of liver disease and the high side effects of current chemotherapies, there is a growing need for a medicine ( $\mathrm{s}$ ) with minimum complications and high effectiveness. In this regard, the use of fish oil omega-3 is most promising, since it has antioxidant and anti-inflammatory properties and shows low side effects. Thus, in this research we tried to examine the possible protective effects of this oil on changes in the levels of gamma glutamyl transferase (GGT), alkaline phosphatase (ALP), lactate dehydrogenase (LDH), serum glutamic oxaloacetic Transaminase (SGOT), serum glutamic pyruvic Transaminase (SGPT), albumin, bilirubin and total protein induced by thioacetamide in pretreated rats.

\section{Methods}

\subsection{Animal Experiments}

This was an experimental study. Animals were collected from Fars Razi vaccine and serum research institute. All guidelines for ethical conduct in the care and use of laboratory animals developed by the ministry of health and Medical education were observed in the present study. 42 adult male wistar rats in a weight range of $200 \pm 10 \mathrm{~g}$ and the age range of 3 - 2.5 months were used. Animals were randomly divided in 6 groups of seven, and kept under standard conditions of $20-22^{\circ} \mathrm{C}$ and light cycle of 12 hours light and 12 hours dark. They had easy access to food and water, and all ethical considerations and animal rights were ensured.

\subsection{Experimental Design}

Animals were divided into 6 groups and were treated as follow: the control which left untreated and subjected to no stress ; the sham 1 which daily received $0.4 \mathrm{~mL} / \mathrm{kg}$ olive oil as a solvent supplement of fish oil omega-3; the sham 2 which received a single dose of $150 \mathrm{mg} / \mathrm{kg}$ thioacetamide; the experimental groups 1,2 and 3 received a daily dose of 100, 200 and $300 \mathrm{mg} / \mathrm{kg}$ fish oil omega-3 supplements respectively followed by a single dose of $150 \mathrm{mg} / \mathrm{kg}$ thioacetamide (Stigma-Aldrich, Switzerland). Fish oil omega-3 was administered orally for 3 months, and thioacetamide was injected interperitonaly at the end of treating period.

\subsection{Biochemical Study}

As the toxic effects of thioacetamide usually becomes apparent about 2 days after the injection, $48 \mathrm{~h}$ after the last injection, animals were anesthetized with ether (Merck, Germany), and blood samples were taken from the heart. These samples were kept under laboratory conditions for 20 minutes; then, centrifuged at 5000 RPM for 15 minutes (Hettich, Germany) $[14,15]$.

Serum concentrations of various parameters were measured by appropriate methods: SGPT, SGOT and LDH by buffer phosphate method, DGKC and ALP by P-Nitrophenyl phosphate method, AMP and albumen by Bromocresol Green method, total protein by biuret reaction end point method [16], and GGT by enzymatic method (by the kit from Darman Kav, Iran). To measure bilirubin, azo DVD reagents (sulfanilic acid sodium nitrite) were used; they react with bilirubin, producing azo, which is red in alkaline PH. After production, direct bilirubin has a pink color, but after addition of accelerating solution, total bilirubin turns green in alkaline $\mathrm{PH}$ [17].

\subsection{Histological Tests}

After removal, livers were fixed separately in $10 \%$ neutral formalin buffer. The dehydration was done by alcohol with different concentrations (from low to high). For clearing, the tissues were placed in two Xylene containers. Then in the infiltration stage, the tissues were soaked in melted paraffin $\left(65^{\circ} \mathrm{C}\right)$, each for an hour. In the molding stage leukhardt parts were used. Following histological tissue preparation and producing specimen blocks, 4 - 5 micron thick sections were prepared, stained using hematoxylineosin method and studied by light microscope [18]. 


\subsection{Statistical Analysis}

The software program SPSS (Version18, Chicago, IL, USA) and statistical ANOVA test were used for data analysis. In order to study statistically significant differences among data, the Tukey HSD test was used and significant average difference was sat at $\mathrm{P}<0.05$. The serum concentrations of GGT, LDH, ALP, SGPT, SGOT, total protein, albumin and bilirubin are presented as average deviation.

\section{Results}

The mean serum concentration of SGOT significantly increased in the sham 2 (receiving thioacetamide alone) and experimental groups 2 and 3 (receiving both fish oil omega-3 supplements and thioacetamide) compared with the control and sham 1, while it showed an insignificant reduction in experimental groups 2 and 3 compared with the sham 2 (Table 1). Similarly, the mean serum level of SGPT significantly increased in the sham 2 and experimental group 2 relative to the control and sham 1, whereas significantly decreased in the experimental group 1 (receiving both $100 \mathrm{mg} / \mathrm{kg}$ fish oil omega-3 supplement and thioacetamide) compared with the sham 2 (recipient of thioacetamide alone) $(\mathrm{P}<0.05)$. Conversely, in respect to mean concentrations of ALP, there were no significant differences among various experimental groups and the sham 2, nor were any such difference among the sham 2, and control and sham 1 group (Table 1 ).

In addition, the mean serum concentration of bilirubin significantly increase in the sham 2 group relative to the control and sham 1 groups, while it showed no significant changes in all experimental groups relative to the control and sham 1 groups, but significantly decreased in all three experimental groups, and the group receiving thioacetamide $(\mathrm{P}<0.05)$. Also, In regard to concentration of total protein, no significant changes were observed between group receiving thioacetamide, and the control and sham 1 group as well as between various experimental groups, and the control, sham 1 and sham 2 groups (Table 2).

In contrast, the mean levels of albumen significantly increased in group receiving thioacetamide compared with the control and sham 1 group, whereas it showed no significant changes in all experimental groups relative to the control and sham 1 groups, but a significant decline was seen between all three experimental groups, and the group receiving thioacetamide (Table 2). The mean concentrations of GGT and LDH significantly increased in the sham 2 group compared with the control and sham 1 group. Nevertheless, the mean level of GGT did not show a significant change in all three experimental groups relative to the control and sham 1 group while the mean level of LDH significantly increased in these groups. Conversely, the average concentration of GGT in experimental groups 1 and 2 (receiving 100 and $200 \mathrm{mg} / \mathrm{kg}$ fish oil omega-3 supplement and thioacetamide respectively) significantly decreased relative to the sham 2 group whereas no differences was observed in the mean concentration of LDH among all three experimental groups and the sham 2 group $(\mathrm{P}<0.05$; Table 2$)$.

\subsection{Histological Findings}

Histological studies of hepatic samples showed normal hepatocytes with protected cytoplasm and marked nuclei in the control and sham 1 group (Figure 1A and 1B). In contrast, tissue sections in the sham 2 group (recipient of thioacetamide) in comparison with the control and sham 1 groups indicated hepatocyte necrosis, increase in mitosis, cell death, abnormal mitotic inflammation in portal space and large nuclei (Figure 1C). Although tissue samples of the experimental groups 1 and 2 (receiving 100 and $200 \mathrm{mg} / \mathrm{kg}$ fish oil omega-3 supplement and thioacetamide) showed no hepatocyte mitosis, apoptosis and necrosis, they had large nuclei (Figures $1 \mathrm{D}$ and $1 \mathrm{E}$ ), whereas the experimental group 3 (recipient of $300 \mathrm{mg} / \mathrm{kg}$ fish oil omega-3 supplement and thioacetamide) showed normal liver tissue (Figure $1 \mathrm{~F})$.

\section{Discussion}

Liver injury was also determined by biochemical parameters (plasma SGPT, SGOT, ALP, LDH levels). Many useful medicines such as acetaminophen, and some industrial and environmental toxins can cause severe liver damage through functional interference with reactive free radicals. One of these industrial toxins is thioacetamide. This toxin induces hepatic centrilobular necrosis, liver cirrhosis and hepatocellular carcinoma (HCC) [19]

According to the results of this study, the values of albumin, bilirubin, SGPT, SGOT, LDH, GGT in groups treated with thioacetamide significantly increased compared to the control and sham1 group. The average concentration of SGPT in the experimental group which received 100 $\mathrm{mg} / \mathrm{kg}$ of fish oil omega-3 supplement and thioacetamide showed a significant decrease compared to the group receiving thioacetamide. The mean serum albumin concentration in all experimental groups receiving fish oil omega3 supplement and thioacetamide significantly decreased compared to the thioacetamide group. The average concentration of billirubin in the experimental groups which received $100 \mathrm{mg} / \mathrm{kg}$ of fish oil omega-3 supplement and thioacetamide showed a significant decrease compared to the group receiving thioacetamide. The mean serum GGT 
Table 1. The Effects of Different Amounts of Fish Oil Omega-3 Supplement on Various Biochemical Serum Parameters in Male Rats Poisoned by Thioacetamide

\begin{tabular}{|c|c|c|c|c|}
\hline All Group & SGPT, (U/L) & SGOT, (U/L) & ALP, $(I U / L)$ & Bilirubin, $(\mathrm{mg} / \mathrm{dL})$ \\
\hline Control & $189.60 \pm 10.60^{\mathrm{a}}$ & $83 / 66 \pm 1.17^{\mathrm{a}}$ & $1456.66 \pm 54.66$ & $0.12 \pm 0.015^{\mathrm{a}}$ \\
\hline Sham 1 & $201 \pm 6.70^{\mathrm{a}}$ & $88 \pm 2.19^{a}$ & $1418 \pm 70.84$ & $0.23 \pm 0.029$ \\
\hline Sham 2 (TAA) & $361 \pm 10.01$ & $187.50 \pm 1.44$ & $1173 \pm 70.15$ & $0.38 \pm 0.015$ \\
\hline $100 \mathrm{mg} / \mathrm{kg}$ omega3+TAA & $234.75 \pm 12.61^{b}$ & $147.25 \pm 10.75$ & $1418 \pm 52.47$ & $0.06 \pm 0.013^{\mathrm{b}}$ \\
\hline $300 \mathrm{mg} / \mathrm{kg}$ omega3+TAA & $278.75 \pm 7.49$ & $165.25 \pm 13.38^{c}$ & $1377 \pm 88.04$ & $0.14 \pm 0.026$ \\
\hline
\end{tabular}

Abbreviations: ALP, Alkaline Phosphatase; SGOT, Serum Glutamic Oxaloacetic Transaminase; SGPT, Serum Glutamic Pyruvic Transaminase.

${ }^{a}$ Represents significant differences between group receiving thioacetamide alone (the sham 2), and the control and sham 1 groups at the level of $\mathrm{P}<0.05$.

${ }^{\mathrm{b}}$ Represents significant differences between the sham 2 group, and various experimental groups (fish oil omega-3 supplement and thioacetamide) at the level of $\mathrm{P}<$ 0.05.

${ }^{\mathrm{c}}$ Represents significant differences among different experimental groups, and control and sham 1 groups at the level of $\mathrm{P}<0.05$.

Table 2. The Effects of Different Amounts of Fish Oil Omega-3 Supplement on Various Biochemical Serum Parameters in Male Rats Poisoned by Thioacetamide

\begin{tabular}{|c|c|c|c|c|}
\hline All Group & Total protein $(\mathrm{mg} / \mathrm{dL})$ & $\operatorname{Albumin}(\mathbf{m g} / \mathbf{d L})$ & $\mathbf{G G T}(\mathbf{U} / \mathbf{L})$ & $\mathbf{L D H}(\mathbf{U} / \mathbf{L})$ \\
\hline Control & $8.88 \pm 0.5$ & $4.30 \pm 0.03^{\mathrm{a}}$ & $2 \pm 0.26^{\mathrm{a}}$ & $554.28 \pm 6.58^{\mathrm{a}}$ \\
\hline Sham 1 & $8.70 \pm 0.07$ & $4.30 \pm 0.04^{\mathrm{a}}$ & $2.50 \pm 0.22^{\mathrm{a}}$ & $599.66 \pm 33.84^{\mathrm{a}}$ \\
\hline Sham 2 (TAA) & $8.56 \pm 0.08$ & $4.70 \pm 0.00$ & $4.50 \pm 0.28$ & $849 \pm 0.57$ \\
\hline $100 \mathrm{mg} / \mathrm{kg}$ omega3+TAA & $8.58 \pm 0.05$ & $4.40 \pm 0.02^{\mathrm{b}}$ & $2.17 \pm 0.15^{b}$ & $962.75 \pm 18.17^{c}$ \\
\hline $200 \mathrm{mg} / \mathrm{kg}$ omega3+TAA & $8.53 \pm 0.20$ & $4.32 \pm 0.10^{\mathrm{b}}$ & $2.20 \pm 0.18^{\mathrm{b}}$ & $955.25 \pm 9.59^{c}$ \\
\hline $300 \mathrm{mg} / \mathrm{kg}$ omega3+TAA & $8.63 \pm 0.24$ & $4.34 \pm 0.10^{\mathrm{b}}$ & $3.75 \pm 0.25$ & $1022 \pm 30.23^{c}$ \\
\hline
\end{tabular}

Abbreviations: GGT, Gamma Glutamyl Transferase; LDH, Lactate Dehydrogenase.

${ }^{\mathrm{a}}$ Represents significant differences between group receiving thioacetamide alone (the sham 2), and the control and sham 1 group at the level of $\mathrm{P}<0.05$.

${ }^{\mathrm{b}}$ Represents significant differences between the sham 2 group, and various experimental groups (fish oil omega-3 supplement and thioacetamide) at the level of $\mathrm{P}<$ 0.05 .

${ }^{\mathrm{c}}$ Represents significant differences among different experimental groups, and the control and sham 1 group at the level of $\mathrm{P}<0.05$.

in the experimental groups receiving $100,200 \mathrm{mg} / \mathrm{kg}$ of fish oil omega-3 supplement and thioacetamide significantly decreased. This means that the fish oil omega-3 supplement had protective effects on liver cells against damage caused by thioacetamide. The histopathological studies also confirmed these results.

Similarly, Chen et al. showed that DHA has beneficial effects on cholestatic liver disease. The beneficial effects of DHA supplement are related to its strong antiinflammatory and anti-oxidative effects as well as downregulation of NF-kB, signaling of the transforming growth factor-beta and Smad protein through functional interference in the activity of extracellular signal regulating kinase (ERK) [20]. More recently, Sherif et al. found that cod liver oil can improve damage induced by sodium nitrite through several mechanisms, including blocking of cell death signs, fibrotic mediators and inflammatory cytokines induced by sodium nitrite [21]. Other evidence showed that DHA supplement and fish oil EPA omega-3 may be the preventive agents in the treatment of liver cir- rhosis in mice [22].

According to Li et al. showed that consumption of diet containing fish oil can reduce systemic inflammation and liver damage induced by infection through up-regulation of the peroxisome proliferator-activated receptor gammamediated pathway (PPAR) in septic mice [23]. Also, Jangale et al. determined that fish oil and flax seed oil can alleviate inflammation in diabetic mice induced by streptozotocinnicotinamide [24]. Kim et al. showed that diet containing omega-3 can attenuate Hepatic damage caused by ischemia and tissue Reperfusion via reduction of NF-Kb activity [25]. At the same time, Popescu et al. indicated that omega-3 fatty acid along with diet containing natural calorie and diet with natural lipid has protective effects on nonalcoholic fatty liver disease [26]. Other studies have shown that fish oil diet prevents hepatocyte cancer in B6C3F1 mice [27]. Similarly, omega-3-rich fish oil improves liver damage caused by LPS through the inhibition of TLR4 signaling pathway and NOD [28].

De Meijer et al. showed that emulsion based on fish oil 

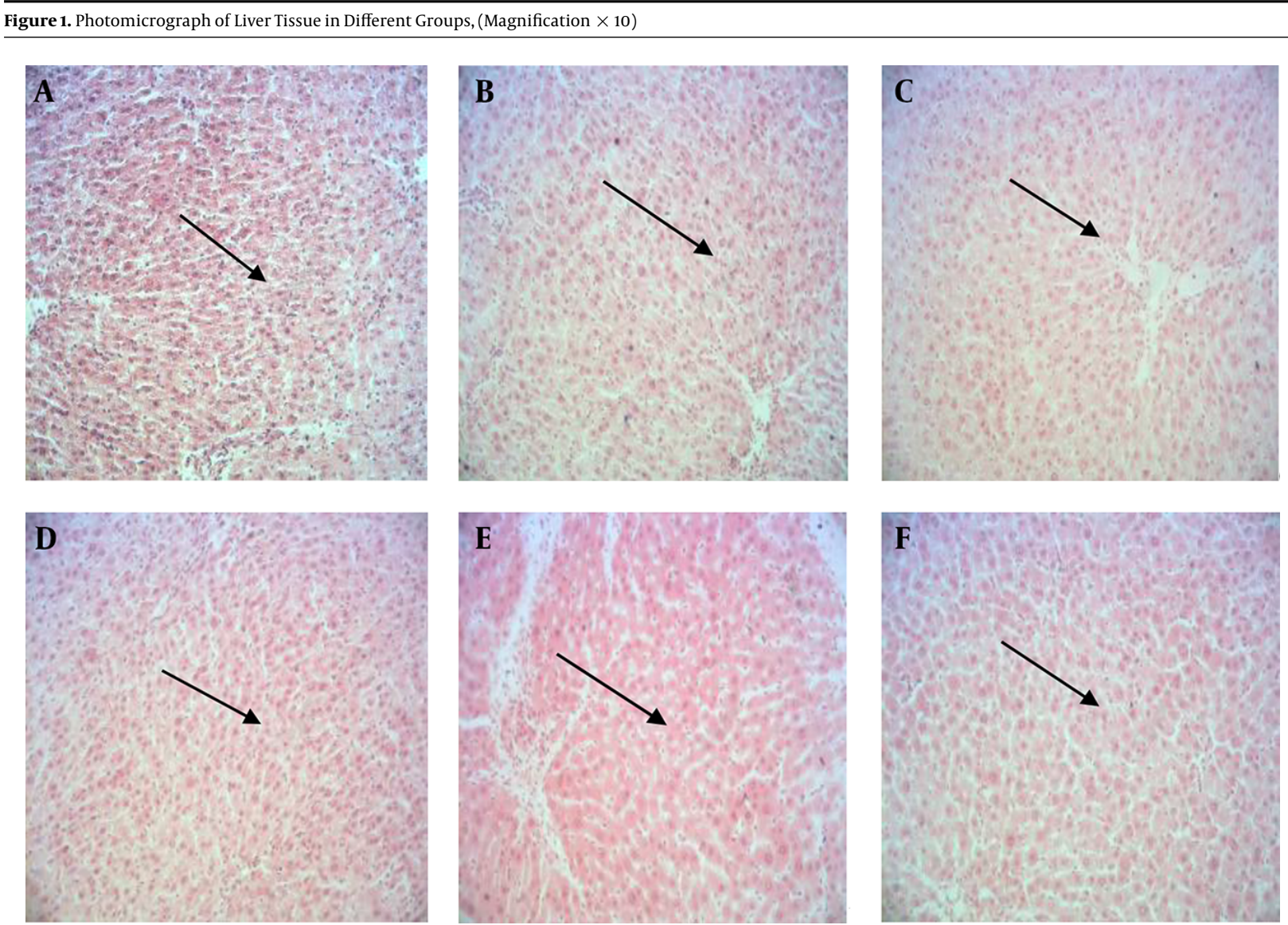

A, Hepatic tissue of the control group showing normal hepatocytes with protected cytoplasm and marked nuclei; B, hepatic tissue of the sham 1 group showing normal hepatocytes with protected cytoplasm and marked nuclei; $C$, hepatic tissue of the sham 2 group (receiving thioacetamide) showing hepatocyte necrosis, increase in mitosis, cell death, abnormal mitotic inflammation in portal space and large nuclei; $\mathrm{D}$, hepatic tissue of the experimental group 1 (receiving $100 \mathrm{mg} / \mathrm{kg}$ fish oil omega-3 and thioacetamide) showing no hepatocyte mitosis, apoptosis and necrosis, but still have large nuclei; E, hepatic tissue of the experimental group 2 (receiving $200 \mathrm{mg} / \mathrm{kg}$ fish oil omega-3 and thioacetamide) showing no hepatocyte mitosis, apoptosis and necrosis, but still have large nuclei; F, hepatic tissue of the experimental group 3 (receiving $300 \mathrm{mg} / \mathrm{kg}$ fish oil omega-3 and thioacetamide) showing regeneration of liver tissue to natural state; hepatocytes have normal size nuclei, and mitosis and apoptosis are not seen.

prevents parenteral nutrition-associated liver disease [29]. Also, Khan et al. demonstrated that fish and flax seed oil can protect against apoptosis, tissue damage and hepatotoxicity induced by nitric oxide; it can reduce lipid peroxidation and improve body's antioxidant system [30]. Other research showed that the cod liver oil improves hepatic damage induced by sodium nitrite via oxidative stress alleviation, and blocking of MCP-1 and mitochondrial functional response as well as reducing DNA fragmentation [31]. It was also found that due to the presence of the antioxidant compounds, omega-3, lipid emulsion based on fish oil prevents liver diseases associated with intestinal failure [32], since omega-3 fatty acid improves the hepatic inflammatory responses by suppressing inflammatory cytokine production in hepatocytes. In addition, EPA reduces levels of TNF-a and IL-6 in the hepatocytes [33], and DHA improves hepatic injuries induced by valproate through re- forming of oxidative stresses and inflammation without having any effect on plasma level of valproate [34]. Moreover, it has been shown that addition of fish oil supplement to parental diet reforms the increased levels of hepatic enzymes resulted from hepatic mal-function related to parental nutrition [35]. Studies have shown that 10\% fish oil and $1 \mathrm{~g} \%$ artichoke leaf can restore hepatocellular carcinoma in rats [36]. Lee et al. determined that omega-3 fatty acid can repair hepatocellular damage caused by obstruction of the bile ducts [37]; it was also shown that fish oil along with allopurinol and verapamil improve hepatic injuries resulting from ischemia by a significant reduction in oxidative stress and hepatic enzymes [38]. In a study by Mardones et al., it was demonstrated that combination of thyroid hormone and fish oil protocol prevents liver damage resulted from tissue injury and ischemia [39]. Furthermore, omega-3 fatty acid prevents acute liver defects and 
stimulates liver regeneration following 90\% hepatectomy in rats [40]. Chiang et al. showed that fish oil can stimulate anti cell proliferation effect of 1- alpha 25-dihydroxy vitamin D3 on hepatic cancer cells [41]; EPA can also improve hepatic toxicity, oxidative stress and inflammation induced by valproate [42]. Omega-3 fatty acids down regulate the TNF-a response to lipopolysaccharide insult, as would be seen in sepsis and this may have a direct role in hepatoprotection [43].

In general the results of this study are in line with the results of other studies. It seems that the oral administration of fish oil omega-3 supplement has protective effect on thioacetamide induced liver toxicity by neutralizing free radicals, stimulating the activity of antioxidant enzymes, and reducing the production of inflammatory cytokinin. As no similar study on the protective effects of fish oil omega-3 supplement on hepatic enzymes and histological changes could be found, it was not possible do a comparative study in this respect. Anyhow, more studies should be conducted to examine the hepatic antioxidant enzymes and molecular changes inducing apoptosis so that the effects of fish oil omega-3 supplement on healing liver toxicity can be determined with higher certainty.

In general, the results of present study showed that fish oil omega-3 supplement in rat model with hepatic malfunction can cause desirable improvements. Thus, if supported by more experiments, it is possible to add fish oil omega-3 supplement to the diet of patients with liver malfunction.

\section{Acknowledgments}

Hereby the authors express their deep appreciation for the sincere cooperation devoted to them by the research deputy of Shiraz Azad University to conduct this research. The results described in this paper are part of a PhD thesis No. 16330509931001.

\section{Footnotes}

Authors' Contribution: Davood Moghadamnia contributed in sample collection and was responsible for functional tests. Mokhtar Mokhtari and Saeed Khatamsaz have been involved in study design and experimental investigation.

Conflict of Interests: The authors declare that they have no conflict of interests.

Funding/Support: This study has been funded by Shiraz Islamic Azad University.

\section{References}

1. Abboud G, Kaplowitz N. Drug-induced liver injury. Drug Saf. 2007;30(4):277-94. [PubMed: 17408305].

2. Medina J, Moreno-Otero R. Pathophysiological basis for antioxidant therapy in chronic liver disease. Drugs. 2005;65(17):2445-61. doi: 10.2165/00003495-200565170-00003. [PubMed: 16296871].

3. Girish C, Pradhan SC. Drug development for liver diseases: focus on picroliv, ellagic acid and curcumin. Fundam Clin Pharmacol. 2008;22(6):623-32. doi: 10.1111/j.1472-8206.2008.00618.x. [PubMed: 19049667].

4. Plourde M, Cunnane SC. Extremely limited synthesis of long chain polyunsaturates in adults: implications for their dietary essentiality and use as supplements. Appl Physiol Nutr Metab. 2007;32(4):619-34. doi: 10.1139/H07-034. [PubMed: 17622276].

5. Wergedahl H, Gudbrandsen OA, Rost TH, Berge RK. Combination of fish oil and fish protein hydrolysate reduces the plasma cholesterol level with a concurrent increase in hepatic cholesterol level in high-fat-fed Wistar rats. Nutrition. 2009;25(1):98-104. doi: 10.1016/j.nut.2008.07.005. [PubMed: 18752928].

6. Kim EH, Bae JS, Hahm KB, Cha JY. Endogenously synthesized n3 polyunsaturated fatty acids in fat- 1 mice ameliorate high-fat diet-induced non-alcoholic fatty liver disease. Biochem Pharmacol. 2012;84(10):1359-65. doi: 10.1016/j.bcp.2012.08.029. [PubMed: 22981383].

7. Haast RA, Kiliaan AJ. Impact of fatty acids on brain circulation, structure and function. Prostaglandins Leukot Essent Fatty Acids. 2015;92:314. doi: 10.1016/j.plefa.2014.01.002. [PubMed: 24485516].

8. Siegel G, Ermilov E. Omega-3 fatty acids: benefits for cardiocerebro-vascular diseases. Atherosclerosis. 2012;225(2):291-5. doi: 10.1016/j.atherosclerosis.2012.09.006. [PubMed: 23031363].

9. Zhu XH, Wu YF, Qiu YD, Jiang CP, Ding YT. Liver-protecting effects of omega-3 fish oil lipid emulsion in liver transplantation. World J Gastroenterol. 2012;18(42):6141-7. doi: 10.3748/wjg.v18.i42.6141. [PubMed: 23155344].

10. Shaaban AA, Shaker ME, Zalata KR, El-kashef HA, Ibrahim TM. Modulation of carbon tetrachloride-induced hepatic oxidative stress, injury and fibrosis by olmesartan and omega-3. Chem Biol Interact. 2014;207:81-91. doi: 10.1016/j.cbi.2013.10.008. [PubMed: 24144775].

11. Wu Z, Qin J, Pu L. Omega-3 fatty acid improves the clinical outcome of hepatectomized patients with hepatitis B virus (HBV)associated hepatocellular carcinoma.J Biomed Res. 2012;26(6):395-9. doi: 10.7555/JBR.26.20120058. [PubMed: 23554777].

12. Natarajan SK, Thomas S, Ramamoorthy P, Basivireddy J, Pulimood $\mathrm{AB}$, Ramachandran A, et al. Oxidative stress in the development of liver cirrhosis: a comparison of two different experimental models. J Gastroenterol Hepatol. 2006;21(6):947-57. doi: 10.1111/j.14401746.2006.04231.x. [PubMed: 16724977].

13. Chilakapati J, Shankar K, Korrapati MC, Hill RA, Mehendale HM. Saturation toxicokinetics of thioacetamide: role in initiation of liver injury. Drug Metab Dispos. 2005;33(12):1877-85. doi: 10.1124/dmd.105.005520. [PubMed:16183780].

14. Sirag HM. Biochemical studies on thioacetamide toxicity in male albino rats and the role of tomato juice as an antioxidant. Mansoura J Forensic Med Clin Toxicol. 2007;99-114.

15. Goksu Erol AY, Bulbul A, Avci G, Ozdemir M, Akkaya O. The protective effects of omega 3 fatty acids and seasame oil on cyclosporine -A induced liver apoptosis. Orig Invest/Ozgum Arastirma. 2011;8-11.

16. Mostafavi-Pour Z, Zal F, Monabati A, Vessal M. Protective effects of a combination of quercetin and vitamin $\mathrm{E}$ against cyclosporine Ainduced oxidative stress and hepatotoxicity in rats. Hepatol Res. 2008;38(4):385-92. doi: 10.1111/j.1872-034X.2007.00273.x. [PubMed: 17927767].

17. Al-Attar AM. Attenuating effect of Ginkgo biloba leaves extract on liver fibrosis induced by thioacetamide in mice. J Biomed Biotechnol. 2012;2012:761450. doi: 10.1155/2012/761450. [PubMed: 23091357]. 
18. Alkiyumi SS, Abdullah MA, Alrashdi AS, Salama SM, Abdelwahab SI, Hadi AH. Ipomoea aquatica extract shows protective action against thioacetamide-induced hepatotoxicity. Molecules. 2012;17(5):6146-55. doi: 10.3390/molecules17056146. [PubMed: 22617138].

19. Stankova P, Kucera O, Lotkova H, Rousar T, Endlicher R, Cervinkova $Z$. The toxic effect of thioacetamide on rat liver in vitro. Toxicol In Vitro. 2010;24(8):2097-103. doi: 10.1016/j.tiv.2010.06.011. [PubMed: 20600801].

20. Chen WY, Lin SY, Pan HC, Liao SL, Chuang YH, Yen YJ, et al. Beneficial effect of docosahexaenoic acid on cholestatic liver injury in rats. J Nutr Biochem. 2012;23(3):252-64. doi: 10.1016/j.jnutbio.2010.11.022. [PubMed: 21497498].

21. Sherif IO, Al-Gayyar MM. Cod liver oil in sodium nitrite induced hepatic injury: does it have a potential protective effect?. Redox Rep. 2015;20(1):11-6. doi: 10.1179/1351000214Y.0000000097. [PubMed: 24945989].

22. Roy R, Chandrasekhar D, Pujari P. Dietary fish oil as hepatoprotective agent in Mus musculus. Indian JExp Biol. 2007;45(4):367-70. [PubMed 17477309].

23. Li CC, Yang HT, Hou YC, Chiu YS, Chiu WC. Dietary fish oil reduces systemic inflammation and ameliorates sepsis-induced liver injury by up-regulating the peroxisome proliferator-activated receptor gamma-mediated pathway in septic mice. J Nutr Biochem. 2014;25(1):19-25. doi: 10.1016/j.jnutbio.2013.08.010. [PubMed: 24314861].

24. Jangale NM, Devarshi PP, Dubal AA, Ghule AE, Koppikar SJ, Bodhankar SL, et al. Dietary flaxseed oil and fish oil modulates expression of antioxidant and inflammatory genes with alleviation of protein glycation status and inflammation in liver of streptozotocinnicotinamide induced diabetic rats. Food Chem. 2013;141(1):187-95. doi: 10.1016/j.foodchem.2013.03.001. [PubMed: 23768346].

25. Kim K, Jung N, Lee K, Choi J, Kim S, Jun J, et al. Dietary omega-3 polyunsaturated fatty acids attenuate hepatic ischemia/reperfusion injury in rats by modulating toll-like receptor recruitment into lipid rafts. Clin Nutr. 2013;32(5):855-62. doi: 10.1016/j.clnu.2012.11.026. [PubMed 23395256].

26. Popescu LA, Virgolici B, Lixandru D, Miricescu D, Condrut E, Timnea $\mathrm{O}$, et al. Effect of diet and omega-3 fatty acids in NAFLD. Rom J Morphol Embryol. 2013;54(3 Suppl):785-90. [PubMed: 24322028].

27. Zhou GD, Zhu H, Phillips TD, Wang J, Wang SZ, Wang F, et al. Effects of dietary fish oil on the depletion of carcinogenic PAH-DNA adduct levels in the liver of B6C3F1 mouse. PLoS One. 2011;6(10):e26589. doi 10.1371/journal.pone.0026589. [PubMed: 22066002].

28. Chen F, Liu Y, Zhu H, Hong Y, Wu Z, Hou Y, et al. Fish oil attenuates liver injury caused by LPS in weaned pigs associated with inhibition of TLR4 and nucleotide-binding oligomerization domain protein signaling pathways. Innate Immun. 2013;19(5):504-15. doi 10.1177/1753425912472003. [PubMed: 23339927].

29. de Meijer VE, Gura KM, Le HD, Meisel JA, Puder M. Fish oil-based lipid emulsions prevent and reverse parenteral nutrition-associated liver disease: the Boston experience. JPEN J Parenter Enteral Nutr 2009;33(5):541-7. doi: 10.1177/0148607109332773. [PubMed: 19571170].

30. Khan MW, Priyamvada S, Khan SA, Khan S, Gangopadhyay A, Yusufi AN Fish/flaxseed oil protect against nitric oxide-induced hepatotoxicity and cell death in the rat liver. Hum Exp Toxicol. 2016;35(3):302-11. doi: 10.1177/0960327115586207. [PubMed: 25964379].
31. Salama MF, Abbas A, Darweish MM, El-Hawwary AA, Al-Gayyar MM. Hepatoprotective effects of cod liver oil against sodium nitrite toxicity in rats. Pharm Biol. 2013;51(11):1435-43. doi: 10.3109/13880209.2013.796564. [PubMed: 23862714].

32. Goulet OJ. Intestinal failure-associated liver disease and the use of fish oil-based lipid emulsions. World Rev Nutr Diet. 2015;112:90-114. doi: 10.1159/000365604. [PubMed: 25471806].

33. Hao W, Wong OY, Liu X, Lee P, Chen Y, Wong KK. omega-3 fatty acids suppress inflammatory cytokine production by macrophages and hepatocytes. J Pediatr Surg. 2010;45(12):2412-8. doi: 10.1016/j.jpedsurg.2010.08.044. [PubMed: 21129557].

34. Abdel-Dayem MA, Elmarakby AA, Abdel-Aziz AA, Pye C, Said SA, ElMowafy AM. Valproate-induced liver injury: modulation by the omega-3 fatty acid DHA proposes a novel anticonvulsant regimen. Drugs RD. 2014;14(2):85-94. doi: 10.1007/s40268-014-0042-z. [PubMed: 24733439].

35. Badia-Tahull MB, Leiva-Badosa E, Jodar-Masanes R, Ramon-Torrell JM, Llop-Talaveron J. The relationship between the parenteral dose of fish oil supplementation and the variation of liver function tests in hospitalized adult patients. Nutr J. 2015;14:65. doi: 10.1186/s12937-015-00486. [PubMed: 26133968].

36. Metwally NS, Kholeif TE, Ghanem KZ, Farrag AR, Ammar NM, AbdelHamid AH. The protective effects of fish oil and artichoke on hepatocellular carcinoma in rats. Eur Rev Med Pharmacol Sci. 2011;15(12):142944. [PubMed: 22288304].

37. Lee S, Kim S, Le HD, Meisel J, Strijbosch RA, Nose V, et al. Reduction of hepatocellular injury after common bile duct ligation using omega-3 fatty acids. J Pediatr Surg. 2008;43(11):2010-5. doi: 10.1016/j.jpedsurg.2008.05.030. [PubMed: 18970933].

38. Messiha BA, Abo-Youssef AM. Protective effects of fish oil, allopurinol, and verapamil on hepatic ischemia-reperfusion injury in rats. J Nat Sci Biol Med. 2015;6(2):351-5. doi: 10.4103/0976-9668.160003. [PubMed: 26283828].

39. Mardones M, Valenzuela R, Romanque P, Covarrubias N, Anghileri F, Fernandez V, et al. Prevention of liver ischemia reperfusion injury by a combined thyroid hormone and fish oil protocol. $J$ Nutr Biochem. 2012;23(9):1113-20. doi: 10.1016/j.jnutbio.2011.06.004. [PubMed: 22137030].

40. Qiu YD, Wang S, Yang Y, Yan XP. Omega-3 polyunsaturated fatty acids promote liver regeneration after 90\% hepatectomy in rats. World J Gastroenterol. 2012;18(25):3288-95. doi: 10.3748/wjg.v18.i25.3288. [PubMed: 22783054].

41. Chiang KC, Persons KS, Istfan NW, Holick MF, Chen TC. Fish oil enhances the antiproliferative effect of 1alpha,25-dihydroxyvitamin D3 on liver cancer cells. Anticancer Res. 2009;29(9):3591-6. [PubMed: 19667153].

42. El-Mowafy AM, Abdel-Dayem MA, Abdel-Aziz A, El-Azab MF, Said SA. Eicosapentaenoic acid ablates valproate-induced liver oxidative stress and cellular derangement without altering its clearance rate: dynamic synergy and therapeutic utility. Biochim Biophys Acta. 2011;1811(7-8):460-7. doi: 10.1016/j.bbalip.2011.04.014. [PubMed: 21571092].

43. Babcock T, Helton WS, Espat NJ. Eicosapentaenoic acid (EPA): an antiinflammatory omega-3 fat with potential clinical applications. Nutrition. 2000;16(11-12):1116-8. doi: 10.1016/S0899-9007(00)00392-0. [PubMed: 11118844]. 